\title{
Theoretical Study of the Auto-catalyzed Hydrolysis Reaction of Sulfur Dioxide
}

Jingjing Liu, ${ }^{\dagger}$ Sheng Fang, ${ }^{\dagger}$ Qiming Bing,,${ }^{\dagger}$ Fu-Ming Tao,,${ }^{*}+$ Jing-yao Liu ${ }^{*}, \dagger$

'Institute of Theoretical Chemistry, Jilin University, Changchun 130023, People's Republic of China.

Department of Chemistry and Biochemistry, California State University, Fullerton, California 92834, United States

\begin{abstract}
The hydrolysis reaction of sulfur dioxide $\left(\mathrm{SO}_{2}\right)$ to form sulfurous acid involving additional sulfurous acid $\left(\mathrm{H}_{2} \mathrm{SO}_{3}\right)$ was investigated using high-level computational methods. With $\mathrm{H}_{2} \mathrm{SO}_{3}$, the reaction takes place via a double proton transfer process with a cage-like structure, which is different from the planar ring structure involved in a corresponding process with an additional water molecule (served as a catalyst). Our results show that $\mathrm{H}_{2} \mathrm{SO}_{3}$ is a better catalyst than water, as the barrier height for the $\mathrm{H}_{2} \mathrm{SO}_{3}$-catalyzed reaction is only $5.5 \mathrm{kcal} / \mathrm{mol}$, compared to over 25.0 and $15.0 \mathrm{kcal} / \mathrm{mol}$ for the reaction without a catalyst and the $\mathrm{H}_{2} \mathrm{O}$-catalyzed reaction, respectively. In addition, the sulfurous acid dimer from the $\mathrm{H}_{2} \mathrm{SO}_{3}$-catalyzed reaction is more stable than hydrated $\mathrm{H}_{2} \mathrm{SO}_{3}$ from the $\mathrm{H}_{2} \mathrm{O}$-catalyzed reaction. Considering the existence of sulfurous
\end{abstract}


acid in the aqueous phase and acidic aerosols, as well as the importance of $\mathrm{SO}_{2}$ and $\mathrm{H}_{2} \mathrm{O}$ in the atmosphere, our results will have potentially significant implications on the homogeneous and heterogeneous nucleation processes.

Keywords: $\mathrm{SO}_{2}$ hydrolysis; Auto-catalytic reaction; Sulfurous acid; DFT; CCSD(T); Kinetics.

\section{Introduction}

Sulfur dioxide is one of the most important atmospheric pollutants, which is mainly from volcano eruption and the burning of fossil fuels [1]. The reactions of $\mathrm{SO}_{2}$ in the atmosphere contribute to various environmental issues, including acid rain, formation of sulfate aerosols, and production of secondary organic aerosols [2]. As a result, substantial efforts have been dedicated to the understanding of the chemical processes of $\mathrm{SO}_{2}$ in the atmosphere [3-9]. A critical step in many atmospheric processes is the adsorption of $\mathrm{SO}_{2}$ on the gas-liquid surface [10-13]. However, the chemical mechanism for the subsequent reactions of $\mathrm{SO}_{2}$ after adsorption is still poorly understood. The high solubility in water leads to the "wet" deposition of $\mathrm{SO}_{2}$, in which the hydrolysis reaction plays a major role. The hydrolysis reaction of $\mathrm{SO}_{2}$ in the atmosphere has a profound impact on the environment. The reaction contributes to the production of hygroscopic species which will act as seed molecules for aerosol formation [9]. In view of this, the sulfurous acid product may serve as either a donor or an acceptor of hydrogen bond, and thus provide as a precursor capable of oligomers and ultimately condense into atmospheric aerosols [14, 
15]. The hydrolysis reaction of $\mathrm{SO}_{2}$ is kinetically and thermodynamically unfavorable in the gas phase[16, 17], and the complete process has been poorly understood for the past decades.

In the hydrolysis reaction of $\mathrm{SO}_{2}$, an additional water molecule may act as a proton transmitter or serve as a micro solvent, effectively reducing the energy barrier of reaction [18]. Recent efforts have been devoted to finding other species with similar effects in promoting the hydrolysis reaction of $\mathrm{SO}_{2}$. Ammonia, an important ingredient of atmospheric aerosols, has been identified as a better proton transmitter than water in promoting the hydrolysis reaction of $\mathrm{SO}_{2}$ [9]. More specifically, recent computational studies on the hydrolysis reactions of sulfur trioxide [19] and glyoxal [20], for example, suggested that atmospheric acid can dramatically lower the energy barriers of the hydrolysis reactions. Acid catalysis may also be important in the hydrolysis reaction of $\mathrm{SO}_{2}$.

The solution of $\mathrm{SO}_{2}$ is comprised of hydrated $\mathrm{SO}_{2}$, sulfurous acid $\left(\mathrm{H}_{2} \mathrm{SO}_{3}\right)$, and sulfonate ion $\left(\mathrm{HSO}_{3}^{-}\right)[6,11,14]$. As a hydrolysis product, sulfurous acid is also expected to be contained in the acidic aerosols [14]. The characterization and isolation of $\mathrm{H}_{2} \mathrm{SO}_{3}$ is still a challenge in inorganic chemistry due to the kinetic instability of sulfurous acid. However, $\mathrm{H}_{2} \mathrm{SO}_{3}$ has been successfully generated in a neutralization-reionization mass spectrometric experiment [21]. In addition, the solvated sulfurous acid $\mathrm{H}_{2} \mathrm{SO}_{3}-5 \mathrm{H}_{2} \mathrm{O}$ is predicted to be more stable than hydrated sulfur dioxide $\mathrm{SO}_{2}-6 \mathrm{H}_{2} \mathrm{O}$ [6]. In addition, the half-life of $\mathrm{H}_{2} \mathrm{SO}_{3}$ is estimated to be 24 hours at room temperature, and Voegele et al. 
suggested that the dimeric $\mathrm{H}_{2} \mathrm{SO}_{3}$ is thermodynamically more stable than isolated $\mathrm{SO}_{2}$ and $\mathrm{H}_{2} \mathrm{O}$ molecules at $77 \mathrm{~K}$ [22].

In the present work, the hydrolysis reaction of $\mathrm{SO}_{2}$ in the presence of sulfurous acid is studied using theoretical computation. Our primary objective is to know whether or not $\mathrm{H}_{2} \mathrm{SO}_{3}$ could act as an auto-catalyst for the formation of itself. Our next objective is to understand any potential effects of this reaction on the characterization and isolation of $\mathrm{H}_{2} \mathrm{SO}_{3}$ in laboratory. Natural Bonding Orbital (NBO) analysis will be performed to evaluate the nature of the catalytic effect. Kinetic simulations will be conducted over the temperatures 200 320 K. Atmospheric implications of this study will be discussed, particularly on atmospheric aerosol formation and particulate growth.

\section{Computational methods}

Quantum chemical calculations were performed using Gaussian 09 suite of program [23]. Equilibrium geometries corresponding to all local minima and transition states were optimized using the popular B3LYP hybrid density functional method with the cc-pV $(\mathrm{T}+\mathrm{d}) \mathrm{Z}$ basis set. The B3LYP/cc-pV(T+d)Z method has shown to provide reliable results for reactions of hydration of sulfuric acid [24] and the hydrolysis reactions of sulfur trioxide, catalyzed by formic acid [25] and sulfuric acid [19], respectively. Intermolecular interactions, particularly hydrogen bonding, may play an important role in the catalytic effect of $\mathrm{H}_{2} \mathrm{SO}_{3}$ in the hydrolysis reaction of $\mathrm{SO}_{2}$. Second-order Moller-Plesset perturbation method (MP2), which is known reliable in describing 
noncovalent interactions [26-29], was also employed to confirm the adequate treatment of intermolecular interactions. All molecular geometries at the stationary points were re-optimized using MP2/cc-pV(T+d)Z method. Harmonic vibrational frequencies were obtained to verify each equilibrium geometry either at a local minimum or at a first-order saddle point. Furthermore, intrinsic reaction coordinate (IRC) calculations were performed to confirm each transition state that connects the desired reactant and product. Using B3LYP equilibrium geometries, electronic energies were further refined by the single point energy calculations using coupled-cluster theory with single, double, and perturbative triple excitations, $\operatorname{CCSD}(\mathrm{T})$, in conjunction with the extrapolation to the complete basis set limit (CBS) from augmented cc-pVDZ and cc-pVTZ energies. The KiSThelP program [30] was used for the kinetic calculations.

\section{Results and Discussion}

Figures 1 and 2 present the equilibrium geometries involved in the $\mathrm{H}_{2} \mathrm{O}-$ and $\mathrm{H}_{2} \mathrm{SO}_{3}$-catalyzed reactions from B3LYP/cc-pV(T+d)Z and MP2/cc-pV(T+d)Z calculations. It is clear that the geometric parameters from B3LYP calculations are in good agreement with those from MP2 calculations. Overall, the deviations between the two methods are within $0.04 \AA$ in hydrogen-bond lengths and $2.1^{\circ}$ in hydrogen-bond angles. The results confirm that $\mathrm{B} 3 \mathrm{LYP} / \mathrm{cc}-\mathrm{pV}(\mathrm{T}+\mathrm{d}) \mathrm{Z}$ method gives an adequate description of the hydrogen bonds for the systems considered in this work. For simplicity, only the B3LYP geometries will be quoted in the following discussions. 


\section{$\mathrm{H}_{2} \mathrm{O}$-catalyzed reaction}

The catalytic effect of a single water molecule on the gaseous hydrolysis reaction of $\mathrm{SO}_{2}$ was studied previously with quantum chemical methods $[9,16,18]$. In the present study, we recalculated the reaction with a single $\mathrm{H}_{2} \mathrm{O}$ as the catalyst, as well as the reaction without a catalyst, in order to compare consistently with the new reactions to be considered in the study. The potential energy surface (PES) profiles for the naked reaction and for the reactions with the catalysis of a single water molecule, along with the geometries of the stationary points on PES are drawn in Figure 1.

Our calculations have reproduced the catalytic effect of a single water molecule as reported previously. Compared with the naked reaction, the water molecule contributes to a reduction of $14.5 \mathrm{kcal} / \mathrm{mol}$ for the energy barrier, which is in good agreement with the previous reported values in the range of $12.5 \sim 15.4 \mathrm{kcal} / \mathrm{mol}[9,16,18]$.

\section{$\mathrm{H}_{2} \mathrm{SO}_{3}$-catalyzed reaction}

Figure 2 shows a schematic PES along with the geometries of the stationary points.

The hydrolysis reaction of $\mathrm{SO}_{2}$ in the presence of sulfurous acid is initiated from a bimolecular collision, either between $\mathrm{SO}_{2}-\mathrm{H}_{2} \mathrm{O}$ and $\mathrm{H}_{2} \mathrm{SO}_{3}$ or between $\mathrm{H}_{2} \mathrm{SO}_{3}-\mathrm{H}_{2} \mathrm{O}$ and $\mathrm{SO}_{2}$, similar to other three body reactions [19, 31-34]. Both channels involve the reactant complex $\mathrm{SO}_{2}-\mathrm{H}_{2} \mathrm{O}-\mathrm{H}_{2} \mathrm{SO}_{3}$. The formation of reactant complex $\mathrm{SO}_{2}-\mathrm{H}_{2} \mathrm{O}-\mathrm{H}_{2} \mathrm{SO}_{3}$, is 7.6 $\mathrm{kcal} / \mathrm{mol}$ more exothermic than that of the corresponding reactant complex for the water-catalyzed reaction. The formation of the cage-like hydrogen bonding networks is responsible for the added stability in the $\mathrm{SO}_{2}-\mathrm{H}_{2} \mathrm{O}-\mathrm{H}_{2} \mathrm{SO}_{3}$ complex. As seen in Figure 2, 
the reaction proceeds from $\mathrm{SO}_{2}-\mathrm{H}_{2} \mathrm{O}-\mathrm{H}_{2} \mathrm{SO}_{3}$ to the dimeric sulfurous acid $\left(\mathrm{H}_{2} \mathrm{SO}_{3}\right)_{2}$ through the transition state TSsa. The pre-existing $\mathrm{H}_{2} \mathrm{SO}_{3}$ acts as a proton transmitter via a cage-like ring for the double proton transfer process. The reaction mechanism is similar to that for the water-catalyzed reaction. With $\mathrm{H}_{2} \mathrm{SO}_{3}$, however, the energy barrier of the reaction is merely $5.5 \mathrm{kcal} / \mathrm{mol}$. The barrier is dramatically reduced from the naked reaction $\left(\Delta \mathrm{E}_{\text {barrier }}=32.0 \mathrm{kcal} / \mathrm{mol}\right)$ and from the $\mathrm{H}_{2} \mathrm{O}$-catalyzed reaction $\left(\Delta \mathrm{E}_{\text {barrier }}=17.5\right.$ $\mathrm{kcal} / \mathrm{mol}$ ). It is worth mentioning that $\mathrm{H}_{2} \mathrm{SO}_{3}$ is even more effective than a union of five water molecules in reducing the energy barrier for the hydrolysis of $\mathrm{SO}_{2}$. In addition, the pre-existing $\mathrm{H}_{2} \mathrm{SO}_{3}$ is also effective in stabilizing the product, as the product complex $\left(\mathrm{H}_{2} \mathrm{SO}_{3}\right)_{2}$ is thermodynamically more stable than $\mathrm{H}_{2} \mathrm{SO}_{3}-\mathrm{H}_{2} \mathrm{O}$. In conclusion, sulfurous acid is a superior catalyst for the hydrolysis of $\mathrm{SO}_{2}$.

The catalytic effect of $\mathrm{H}_{2} \mathrm{SO}_{3}$

The high catalytic efficiency of $\mathrm{H}_{2} \mathrm{SO}_{3}$ may reside in the increased stabilization in the reactant complexes, which facilitates the proton transfer in the hydrolysis process. The stability of the reactant complexes are enhanced in the order of $\mathrm{SO}_{2}-\mathrm{H}_{2} \mathrm{O}, \mathrm{SO}_{2}-\left(\mathrm{H}_{2} \mathrm{O}\right)_{2}$ and $\mathrm{SO}_{2}-\mathrm{H}_{2} \mathrm{O}-\mathrm{H}_{2} \mathrm{SO}_{3}$. The enhanced stability may be attributed to the favorable hydrogen bonding and certain geometric arrangement. The number of hydrogen bonds increases as a catalyst such as $\mathrm{H}_{2} \mathrm{O}$ or $\mathrm{H}_{2} \mathrm{SO}_{3}$, is added in the reactant complex. In addition, it is clear from Figure 3 that the quasi hexagonal hydrogen bonding networks in $\mathrm{SO}_{2}-\left(\mathrm{H}_{2} \mathrm{O}\right)_{2}$ and $\mathrm{SO}_{2}-\mathrm{H}_{2} \mathrm{O}-\mathrm{H}_{2} \mathrm{SO}_{3}$, respectively, have reduced tension from the quadrilateral network of $\mathrm{SO}_{2}-\mathrm{H}_{2} \mathrm{O}$. It is worth mentioning that the transition state has a similar geometry as the 
corresponding reactant complex. The superior catalytic effect of $\mathrm{H}_{2} \mathrm{SO}_{3}$ may originate from the hydrogen bond networks of the reactant complexes. A linear hydrogen bond $\mathrm{X}-\mathrm{H} \cdots \mathrm{Y}\left(180.0^{\circ}\right)$ is the most favorable, and any deviation from linearity decreases the stability as a result of poor delocalization of electrons from the donor (Y) to the acceptor (X) atom [31]. The delocalization of electrons for the hydrogen bond facilitates the proton transfer to form a covalent H-Y bond. Figure 3 shows that all hydrogen bonds in $\mathrm{SO}_{2}-\mathrm{H}_{2} \mathrm{O}-\mathrm{H}_{2} \mathrm{SO}_{3}$ are closer to linearity than those in $\mathrm{SO}_{2}-\left(\mathrm{H}_{2} \mathrm{O}\right)_{2}$. For example, two of the hydrogen bonds in $\mathrm{SO}_{2}-\mathrm{H}_{2} \mathrm{O}-\mathrm{H}_{2} \mathrm{SO}_{3}$ have bond angels of $168.5^{\circ}$ and $169.5^{\circ}$, which are in contrast to $144.3^{\circ}$ and $162.6^{\circ}$ in $\mathrm{SO}_{2}-\left(\mathrm{H}_{2} \mathrm{O}\right)_{2}$. In addition, the stronger hydrogen bonds or the better delocalization of electrons are reflected by the shorter hydrogen bond lengths in $\mathrm{SO}_{2}-\mathrm{H}_{2} \mathrm{O}-\mathrm{H}_{2} \mathrm{SO}_{3}$ than those in $\mathrm{SO}_{2}-\left(\mathrm{H}_{2} \mathrm{O}\right)_{2}$.

In order to further understand the physical origin of high catalytic efficiency of sulfurous acid, we conducted the NBO analysis of the donor-acceptor interactions in the reactant complexes $\mathrm{SO}_{2}-\mathrm{H}_{2} \mathrm{O}, \mathrm{SO}_{2}-\left(\mathrm{H}_{2} \mathrm{O}\right)_{2}$, and $\mathrm{SO}_{2}-\mathrm{H}_{2} \mathrm{O}-\mathrm{H}_{2} \mathrm{SO}_{3}$, respectively. Figure 4 shows three pairs of interacting molecular orbitals: the $\mathrm{O}_{a}$ lone pair orbital and the S-O antibonding orbital $\left(\mathrm{LP}\left(\mathrm{O}_{\mathrm{a}}\right) \rightarrow \pi^{*}(\mathrm{~S}-\mathrm{O})\right)$, the $\mathrm{O} b$ lone pair orbital and $\mathrm{O}_{\mathrm{a}}-\mathrm{H}$ antibonding orbital $\left(\mathrm{LP}\left(\mathrm{O}_{\mathrm{b}}\right) \rightarrow \delta^{*}\left(\mathrm{O}_{\mathrm{a}}-\mathrm{H}\right)\right)$, and the $\mathrm{O}_{\mathrm{c}}$ lone pair orbital and $\mathrm{O}-\mathrm{H}_{\mathrm{d}}$ antibonding orbital $\left(\mathrm{LP}\left(\mathrm{O}_{\mathrm{c}}\right) \rightarrow \delta^{*}\left(\mathrm{O}-\mathrm{H}_{\mathrm{d}}\right)\right)$. Figure 4 shows the second-order stabilization energies which reflect the strength of the donor-acceptor interactions. The stabilization energies of the $\mathrm{LP}\left(\mathrm{O}_{(\mathrm{a})}\right) \rightarrow \pi^{*}(\mathrm{~S}-\mathrm{O})$ interactions in $\mathrm{SO}_{2}-\mathrm{H}_{2} \mathrm{O}, \mathrm{SO}_{2}-\left(\mathrm{H}_{2} \mathrm{O}\right)_{2}$, and $\mathrm{SO}_{2}-\mathrm{H}_{2} \mathrm{O}-\mathrm{H}_{2} \mathrm{SO}_{3}$ are 1.5, 3.2 , and $5.2 \mathrm{kcal} / \mathrm{mol}$, respectively. The energy values are in the order of $\mathrm{SO}_{2}-\mathrm{H}_{2} \mathrm{O}<$ 
$\mathrm{SO}_{2}-\left(\mathrm{H}_{2} \mathrm{O}\right)_{2}<\mathrm{SO}_{2}-\mathrm{H}_{2} \mathrm{O}-\mathrm{H}_{2} \mathrm{SO}_{3}$. The ordering of the stabilization energies is reflected by the trend in the orbital overlaps (see Figure 4), and is consistent with the intermolecular S... Oa bond distances of the three reactant complexes (see Figure 3). In the meanwhile, the $\mathrm{LP}\left(\mathrm{O}_{\mathrm{b}}\right) \rightarrow \delta^{*}\left(\mathrm{O}_{\mathrm{a}}-\mathrm{H}\right)$ and $\mathrm{LP}\left(\mathrm{O}_{\mathrm{c}}\right) \rightarrow \delta^{*}\left(\mathrm{O}-\mathrm{H}_{\mathrm{d}}\right)$ interactions in $\mathrm{SO}_{2}-\mathrm{H}_{2} \mathrm{O}-\mathrm{H}_{2} \mathrm{SO}_{3}(14.4,8.2$ $\mathrm{kcal} / \mathrm{mol})$ are also stronger than those in $\mathrm{SO}_{2}-\left(\mathrm{H}_{2} \mathrm{O}\right)_{2}(13.9,1.6 \mathrm{kcal} / \mathrm{mol})$. The enhancement of the $\mathrm{LP}\left(\mathrm{O}_{\mathrm{b}}\right) \rightarrow \delta^{*}\left(\mathrm{O}_{\mathrm{a}}-\mathrm{H}\right)$ and $\mathrm{LP}\left(\mathrm{O}_{\mathrm{c}}\right) \rightarrow \delta^{*}\left(\mathrm{O}-\mathrm{H}_{\mathrm{d}}\right)$ interactions is also consistent with the shortening of the $\mathrm{O}_{\mathrm{b}} \cdots \mathrm{H}-\mathrm{O}_{\mathrm{a}}$ and $\mathrm{O}_{\mathrm{c}} \cdots \mathrm{H}_{\mathrm{d}} \mathrm{O}$ hydrogen-bond distances. On the other hand, the $\mathrm{O}_{\mathrm{a}}-\mathrm{H}$ and $\mathrm{O}-\mathrm{H}_{\mathrm{d}}$ covalent bonds are weakened as the hydrogen bonds are strengthened, and ultimately the cleavage of $\mathrm{O}_{\mathrm{a}}-\mathrm{H}$ and $\mathrm{O}-\mathrm{H}_{\mathrm{d}}$ bonds is facilitated to promote the proton transfer in the hydrolysis processes. In conclusion, the presence of sulfurous acid promotes the formation of the $\mathrm{S}-\mathrm{O}_{\mathrm{a}}$ bond and the transfer of a proton in the hydrolysis reaction. Sulfurous acid is shown more effective than a water molecule as a catalyst in promoting the hydrolysis reaction of $\mathrm{SO}_{2}$.

\section{Kinetics analysis}

The hydrolysis reaction of $\mathrm{SO}_{2}$ in the presence of $\mathrm{H}_{2} \mathrm{O}$ or $\mathrm{H}_{2} \mathrm{SO}_{3}$ as a catalyst can be characterized by Eq. 1,

$\mathrm{SO}_{2}-\mathrm{H}_{2} \mathrm{O}+\mathrm{CA} \underset{\mathrm{S}_{2}}{\stackrel{k_{1}}{\longrightarrow}}$ reactant complex $\stackrel{k_{w i}}{\longrightarrow}$ products
$\mathrm{kO}_{2}+\mathrm{CA}-\mathrm{H}_{2} \mathrm{O}$

Applying the steady-state approximation for the reactant complexes $\mathrm{SO}_{2}-\mathrm{H}_{2} \mathrm{O}-\mathrm{H}_{2} \mathrm{SO}_{3}$ and $\mathrm{SO}_{2}-\left(\mathrm{H}_{2} \mathrm{O}\right)_{2}$, and assuming that reactant complexes are in equilibrium with the reactants, the overall rate constant for this reaction can be expressed as 
$k_{t o t}=\frac{k_{1} k_{u n i}}{k_{-1}+k_{u n i}}$

If $k_{\text {uni }}<<k_{-1}$, the rate constant is expresses as

$k_{\text {tot }}=\frac{k_{1} k_{\text {uni }}}{k_{-1}+k_{\text {uni }}}=K_{\text {eq }} k_{\text {uni }}$

where $K_{\text {eq }}$ and $k_{\text {uni }}$ are the equilibrium constants for the formation of reactant complex and the rate constant for the unimolecular isomerization, respectively. $K_{\text {eq }}$ can be obtained by Eq. 4,

$K_{e q}=\frac{k_{1}}{k_{-1}}=\frac{Q_{\mathrm{RC}}}{Q_{\text {reactants }}} \exp \left(-\frac{E_{\mathrm{RC}}-E_{\text {reactants }}}{R T}\right)$

The unimolecular rate constant $k_{\text {uni }}$ was calculated using the transition state theory (TST) with Wigner Tunneling corrections [35], as by Eq. 5,

$k_{\text {uni }}=\Gamma \frac{k_{\mathrm{B}} T}{h} \frac{Q_{\mathrm{TS}}}{Q_{\mathrm{RC}}} \exp \left(-\frac{E_{\mathrm{TS}}-E_{\mathrm{RC}}}{R T}\right)$

In Eqs. 4 and 5, $Q_{\mathrm{RC}}, Q_{\text {reactants }}$ and $Q_{\mathrm{TS}}$ are the total partition functions of the reactant complexes, reactants, and the transitions states, respectively. $E_{\mathrm{RC}}, E_{\text {reactants, }} E_{\mathrm{TS}}$ denote the total energies of the reactant complexes, reactants and transition states, respectively. $\Gamma$ is the corresponding Wigner tunneling correction factor at temperature $T$, which was estimated by Eq. 6 [36], 
$\Gamma=1+\frac{1}{24}\left(\frac{h v^{\neq}}{k_{\mathrm{B}} T}\right)^{2}$

where $v^{\neq}$is the imaginary frequency of the transition state. Note that $k$-1 is much larger than $k_{\text {uni }}$ for the two reaction channels of $\mathrm{H}_{2} \mathrm{O}$-catalyzed reaction and the $\mathrm{SO}_{2}+$ $\mathrm{H}_{2} \mathrm{SO}_{3}-\mathrm{H}_{2} \mathrm{O}$ reaction. As a result, the total rate constant is obtained by Eq. 3, i.e., $k_{\text {tot }}=$ $K_{\text {eq }} k_{\text {uni. }}$ However, in the case of the $\mathrm{SO}_{2}-\mathrm{H}_{2} \mathrm{O}+\mathrm{H}_{2} \mathrm{SO}_{3}$ reaction, $k_{\text {uni }}$ is larger than $k_{-1}$, and the overall rate constant is thus evaluated according to Eq. 2 , in which $k_{l}$ is evaluated by hard-sphere collision theory and $k_{-1}$ is obtained from the expression $k_{-1}=k_{1} / K_{\text {eq }}$. The values of the calculated rate constants for the $\mathrm{H}_{2} \mathrm{O}$-catalyzed and $\mathrm{H}_{2} \mathrm{SO}_{3}$-catalyzed reactions over the temperature range of $200-320 \mathrm{~K}$ are listed in Table 1 . The kinetic data demonstrate that the two channels for the $\mathrm{H}_{2} \mathrm{O}$-catalyzed reaction have similar rate constants, about $10^{-25} \sim 10^{-22} \mathrm{~cm}^{3}$ molecule $\mathrm{e}^{-1} \mathrm{~s}^{-1}$ in the temperature range of $200 \sim 320 \mathrm{~K}$. In the $\mathrm{H}_{2} \mathrm{SO}_{3}$-assited reaction, the reaction of $\mathrm{H}_{2} \mathrm{SO}_{3}$ with $\mathrm{SO}_{2}-\mathrm{H}_{2} \mathrm{O}$ is dominant, with the rate constant varying from $3.41 \times 10^{-10}$ to $2.3 \times 10^{-10}$ under the temperature range of 200 $320 \mathrm{~K}$. From Table 1, it is clear that the rate constants for the $\mathrm{H}_{2} \mathrm{O}$-assisted reaction are far slower than the $\mathrm{H}_{2} \mathrm{SO}_{3}$-catalyzed reaction, as the rate constants are about 15 12 orders of magnitude slower than that of $\mathrm{SO}_{2}-\mathrm{H}_{2} \mathrm{O}+\mathrm{H}_{2} \mathrm{SO}_{3}$ reaction. In fact, sulfurous acid is kinetically unstable under the atmospheric conditions, which restricts the significance of the title reaction in the gas phase. However, given the importance of $\mathrm{SO}_{2}$ and $\mathrm{H}_{2} \mathrm{SO}_{3}$ in contributing the aerosol formation and particle growth, the $\mathrm{H}_{2} \mathrm{SO}_{3}$-assited reaction is important on surfaces of particles and in the bulk-phase droplets. In addition, in an 
aqueous or surface environment, the produced sulfurous acid with oxygen atoms and hydrogen atoms serving as either proton donor or acceptor of hydrogen bonds are capable of forming hydrogen bonds with other aerosol contributors such as water, sulfuric acid or VOC(s), to provide a precursor capable of oligomers, which will provide a potential implication for the particle growth.

\section{Conclusion}

Sulfurous acid is shown to have more effective catalytic roles than water molecule in the gaseous hydrolysis reaction of $\mathrm{SO}_{2}$. In the presence of $\mathrm{H}_{2} \mathrm{SO}_{3}$, the energy barrier is calculated to be only $5.5 \mathrm{kcal} / \mathrm{mol}$, which is a significant drop of more than $20 \mathrm{kcal} / \mathrm{mol}$ relative to the naked reaction. The enhanced stability is attributed to the favorable hydrogen bonding and other geometric properties. In addition, the NBO analysis shows enhanced second-order stabilization energies from the donor-acceptor intermolecular interactions of the reactant complexes in the presence of sulfurous acid with respect to the reactant complexes involving only additional water molecules, a further demonstration of the strong catalytic effect of $\mathrm{H}_{2} \mathrm{SO}_{3}$. The kinetic calculations indicate that the hydrolysis reaction of $\mathrm{SO}_{2}$ is an autocatalytic reaction. The results of the present study may have significant implications on a detailed chemical mechanism for the formation of atmospheric sulfate aerosols.

\section{Corresponding Author}


*Phone: +86-0431-88498016; E-mail: ljy121@jlu.edu.cn

*Phone: +17142784517; E-mail: ftao@fullerton.edu

\section{Acknowledgements}

We thank the National Natural Science Foundation of China (Grants 21373098, 20973077) and the U.S. National Science Foundation (Award 1012994) for the support of this work. The authors are grateful to Computing Center of Jilin Province for essential support.

\section{References}

[1] C. N. Hewitt, The atmospheric chemistry of sulphur and nitrogen in power station plumes, Atmos. Environ. 35 (2001) 1155-1170.

[2] R. Zhang, A. Khalizov, L. Wang, M. Hu, W. Xu, Nucleation and growth of nanoparticles in the atmosphere, Chem. Rev. 112 (2012) 1957-2011.

[3] Y. Zhou, E. P. Rosen, H. Zhang, W. Rattanavaraha, W. Wang, R.M. Kamens, $\mathrm{SO}_{2}$ oxidation and nucleation studies at near-atmospheric conditions in outdoor smog chamber, Environ. Chem. 10 (2013) 210-220.

[4] T. Kurten, J. R. Lane, S. Jorgensen, H.G. Kjaergaard, A Computational study of the oxidation of $\mathrm{SO}_{2}$ to $\mathrm{SO}_{3}$ by gas-phase organic oxidants, J. Phys. Chem. A 115 (2011) 8669-8681.

[5] Y.-Y. Zhao, Y. Zeng Eddy, X.-H. Zhang, F.-M. Tao, Theoretical study of small Water clusters of sulfur dioxide, Chin. J. Struct. Chem. 29 (2010) 499-508. 
[6] R. Steudel, Y. Steudel, Sulfur dioxide and water: structures and energies of the hydrated species $\mathrm{SO}_{2} \cdot \mathrm{nH}_{2} \mathrm{O}$, $\left[\mathrm{HSO}_{3}\right]^{-} \cdot \mathrm{nH}_{2} \mathrm{O},\left[\mathrm{SO}_{3} \mathrm{H}\right]^{-} \cdot \mathrm{nH}_{2} \mathrm{O}$, and $\mathrm{H}_{2} \mathrm{SO}_{3} \cdot \mathrm{nH}_{2} \mathrm{O}(\mathrm{n}=0-8)$, Eur. J. Inorg. Chem. 10 (2009) 1393-1405.

[7] S.-d. Jiang, Z.-h. Wang, J.-h. Zhou, Z.-c. Wen, K.-f. Cen, A quantum chemistry study on reaction mechanisms of $\mathrm{SO}_{2}$ with $\mathrm{O}_{3}$ and $\mathrm{H}_{2} \mathrm{O}_{2}$, J. Zhejiang Univ. Sci. A 10 (2009) $1327-1333$.

[8] T. L. Tarbuck, G. L. Richmond, Adsorption and reaction of $\mathrm{CO}_{2}$ and $\mathrm{SO}_{2}$ at a water surface, J. Am. Chem. Soc. 128 (2006) 3256-3267.

[9] J. Liu, S. Fang, W. Liu, M. Wang, F.-M. Tao, J.-y. Liu, Mechanism of the gaseous hydrolysis reaction of $\mathrm{SO}_{2}$ : effects of $\mathrm{NH}_{3}$ versus $\mathrm{H}_{2} \mathrm{O}$, J. Phys. Chem. A 119 (2015) $102-111$.

[10] E. S. Shamay, K. E. Johnson, G. L. Richmond, Dancing on water: the choreography of sulfur dioxide adsorption to aqueous surfaces, J. Phys. Chem. C, 115 (2011) 25304-25314.

[11] S. T. Moin, L. H. V. Lim, T. S. Hofer, B. R. Randolf, B. M. Rode, Sulfur dioxide in water: structure and dynamics studied by an ab initio quantum mechanical charge field molecular dynamics simulation, Inorg. Chem. 50 (2011) 3379-3386.

[12] M. Baer, C.J. Mundy, T.-M. Chang, F.-M. Tao, L.X. Dang, Interpreting vibrational sum-frequency spectra of sulfur dioxide at the air/water interface: A comprehensive molecular dynamics study, J. Phys. Chem. B 114 (2010) 7245-7249.

[13] T. L. Tarbuck, G. L. Richmond, $\mathrm{SO}_{2}: \mathrm{H}_{2} \mathrm{O}$ surface complex found at the vapor/water 
interface, J. Am. Chem. Soc. 127 (2005) 16806-16807.

[14] T. M. Townsend, A. Allanic, C. Noonan, J.R. Sodeau, Characterization of sulfurous acid, sulfite, and bisulfite aerosol systems, J. Phys. Chem. A 116 (2012) 4035-4046.

[15] J. Herb, Y. Xu, F. Yu, A.B. Nadykto, Large hydrogen-bonded pre-nucleation $\left(\mathrm{HSO}_{4}^{-}\right)\left(\mathrm{H}_{2} \mathrm{SO}_{4}\right)_{\mathrm{m}}\left(\mathrm{H}_{2} \mathrm{O}\right)_{\mathrm{k}}$ and $\left(\mathrm{HSO}_{4}\right)^{-}\left(\mathrm{NH}_{3}\right)\left(\mathrm{H}_{2} \mathrm{SO}_{4}\right)_{\mathrm{m}}\left(\mathrm{H}_{2} \mathrm{O}\right)_{\mathrm{k}}$ clusters in the earth's atmosphere, J. Phys. Chem. A 117 (2013) 133-152.

[16] W.-K. Li, M. L. McKee, Theoretical study of $\mathrm{OH}$ and $\mathrm{H}_{2} \mathrm{O}$ addition to $\mathrm{SO}_{2}$, J. Phys. Chem. A 101 (1997) 9778-9782.

[17] E. Bishenden, D. Donaldson, Ab initio study of $\mathrm{SO}_{2}+\mathrm{H}_{2} \mathrm{O}$, J. Phys. Chem. A, 102 (1998) 4638-4642

[18] T. Loerting, K. R. Liedl, Water-mediated proton transfer: A mechanistic investigation on the example of the hydration of sulfur oxides, J. Phys. Chem. A 105 (2001) 5137-5145.

[19] M. Torrent-Sucarrat, J. S. Francisco, J. M. Anglada, Sulfuric acid as autocatalyst in the formation of sulfuric acid, J. Am. Chem. Soc. 134 (2012) 20632-20644.

[20] M. K. Hazra, J. S. Francisco, A. Sinha, Hydrolysis of glyoxal in water-restricted environments: formation of organic aerosol precursors through formic acid catalysis, J. Phys. Chem. A 118 (2014) 4095-4105.

[21] D. Suelzle, M. Verhoeven, J. K. Terlouw, H. Schwarz, Generation and characterization of sulfurous acid $\left(\mathrm{H}_{2} \mathrm{SO}_{3}\right)$ and of its radical cation as stable species in the gas phase, Angew. Chem., Int. Ed. Engl., 27 (1988) 1533-1534. 
[22] A. E. Voegele, C. S. Tautermann, T. Loerting, A. Hallbrucker, E. Mayer, K.R. Liedl, About the stability of sulfurous acid $\left(\mathrm{H}_{2} \mathrm{SO}_{3}\right)$ and its dimer, Chem.-Eur. J. 8 (2002) 5644-5651.

[23] M. J. Frisch, G. W. Trucks, H. B. Schlegel, G. E. Scuseria, M. A. Robb, J. R. Cheeseman, G. Scalmani, V. Barone, B. Mennucci, G. A. et al., Gaussian 09, revision C.01; Gaussian, Inc.: Wallingford, CT, 2009.

[24] T. Kurten, M. R. Sundberg, H. Vehkamaki, M. Noppel, J. Blomqvist, M. Kulmala, $\mathrm{Ab}$ initio and density functional theory reinvestigation of gas-phase sulfuric acid monohydrate and ammonium hydrogen sulfate, J. Phys. Chem. A, 110 (2006) 7178-7188. [25] B. Long, Z.-w. Long, Y.-b. Wang, X.-f. Tan, Y.-h. Han, C.-y. Long, S.-j. Qin, W.-j. Zhang, Formic Acid Catalyzed Gas-Phase Reaction of $\mathrm{H}_{2} \mathrm{O}$ with $\mathrm{SO}_{3}$ and the Reverse Reaction: A Theoretical Study, Chemphyschem, 13 (2012) 323-329.

[26] W. Zhang, B. Du, Z. Qin, Catalytic Effect of Water, Formic Acid, or Sulfuric Acid on the Reaction of Formaldehyde with OH Radicals, J. Phys. Chem. A, 118 (2014) 4797-4807.

[27] D. E. Husar, B. Temelso, A. L. Ashworth, G. C. Shields, Hydration of the Bisulfate Ion: Atmospheric Implications, J. Phys. Chem. A, 116 (2012) 5151-5163.

[28] R. J. Buszek, M. Torrent-Sucarrat, J.M. Anglada, J.S. Francisco, Effects of a Single Water Molecule on the $\mathrm{OH}+\mathrm{H} 2 \mathrm{O} 2$ Reaction, J. Phys. Chem. A, 116 (2012) 5821-5829.

[29] K. E. Riley, P. Hobza, Assessment of the MP2 method, along with several basis sets, for the computation of interaction energies of biologically relevant hydrogen bonded and 
dispersion bound complexes, J. Phys. Chem. A, 111 (2007) 8257-8263.

[30] S. Canneaux, F. Bohr, E. Henon, KiSThelP: A program to predict thermodynamic properties and rate constants from quantum chemistry results, J. Comput. Chem. 35 (2014) 82-93.

[31] W. Zhang, B. Du, Z. Qin, Catalytic effect of water, formic acid, or sulfuric acid on the reaction of formaldehyde with OH radicals, J. Phys. Chem. A 118 (2014) 4797-4807.

[32] B. Du, W. Zhang, Kinetics and mechanism of the water-assisted reaction of NCO with $\mathrm{CH}_{3} \mathrm{OH}$ : A quantum chemical study, Comput. Theor. Chem. 1044 (2014) 55-61.

[33] R. J. Buszek, J. R. Barker, J. S. Francisco, Water effect on the OH plus $\mathrm{HCl}$ reaction, J. Phys. Chem. A 116 (2012) 4712-4719.

[34] H. A. Rypkema, A. Sinha, J. S. Francisco, Carboxylic acid catalyzed hydration of acetaldehyde, J. Phys. Chem. A 119 (2015) 4581-4588.

[35] K. A. Holbrook, M.J. Pilling, S.H. Robertson, P.J. Robinson, Unimolecular Reactions, second ed., Wiley, New York, 1996.

[36] E. Wigner, Calculation of the rate of elementary association reactions, J. Chem. Phys. 5 (1937) 720-725. 


\section{Figure Captions}

Figure 1. Schematic potential energy surface for the $\mathrm{SO}_{2}+\mathrm{H}_{2} \mathrm{O}$, and $\mathrm{SO}_{2}+2 \mathrm{H}_{2} \mathrm{O}$ reactions. The corresponding geometries have been obtained at B3LYP/cc-pV(T+d)Z and MP2/cc-pV(T+d)Z (in brakets) level of theory. The energy profile has been calculated at the $\operatorname{CCSD}(\mathrm{T}) / \mathrm{CBS} / / \mathrm{B} 3 \mathrm{LYP} / \mathrm{cc}-\mathrm{pV}(\mathrm{T}+\mathrm{d}) \mathrm{Z}$ +ZPE level of theory (bond distances in angstrom, angles in degree).

Figure 2. Schematic potential energy surface for the $\mathrm{SO}_{2}+\mathrm{H}_{2} \mathrm{O}+\mathrm{H}_{2} \mathrm{SO}_{3}$ reaction. The corresponding geometries have been obtained at B3LYP/cc-pV(T+d)Z and $\mathrm{MP} 2 / \mathrm{cc}-\mathrm{pV}(\mathrm{T}+\mathrm{d}) \mathrm{Z}$ (in brakets) level of theory. The energy profile has been calculated at the CCSD(T)/CBS// B3LYP /cc-pV(T+d)Z +ZPE level of theory (bond distances in angstrom, angles in degree).

Figure 3. Structures of reactant complexes $\mathrm{SO}_{2}-\mathrm{H}_{2} \mathrm{O}, \mathrm{SO}_{2}-\left(\mathrm{H}_{2} \mathrm{O}\right)_{2}$ and $\mathrm{SO}_{2}-\mathrm{H}_{2} \mathrm{O}-\mathrm{H}_{2} \mathrm{SO}_{3}$ obtained at B3LYP /cc-pV(T+d)Z level of theory (bond distances in angstrom, angles in degree).

Figure 4. NBO overlaps of donor-acceptor interactions in complexes $\mathrm{SO}_{2}-\mathrm{H}_{2} \mathrm{O}$, $\mathrm{SO}_{2}-\left(\mathrm{H}_{2} \mathrm{O}\right)_{2}$ and $\mathrm{SO}_{2}-\mathrm{H}_{2} \mathrm{O}-\mathrm{H}_{2} \mathrm{SO}_{3}$, respectively $\left(0.05 \mathrm{e} / \AA^{3}\right.$ isosurface from B3LYP /cc-pV(T+d)Z model chemistry). The second-order stabilization energies are given. 


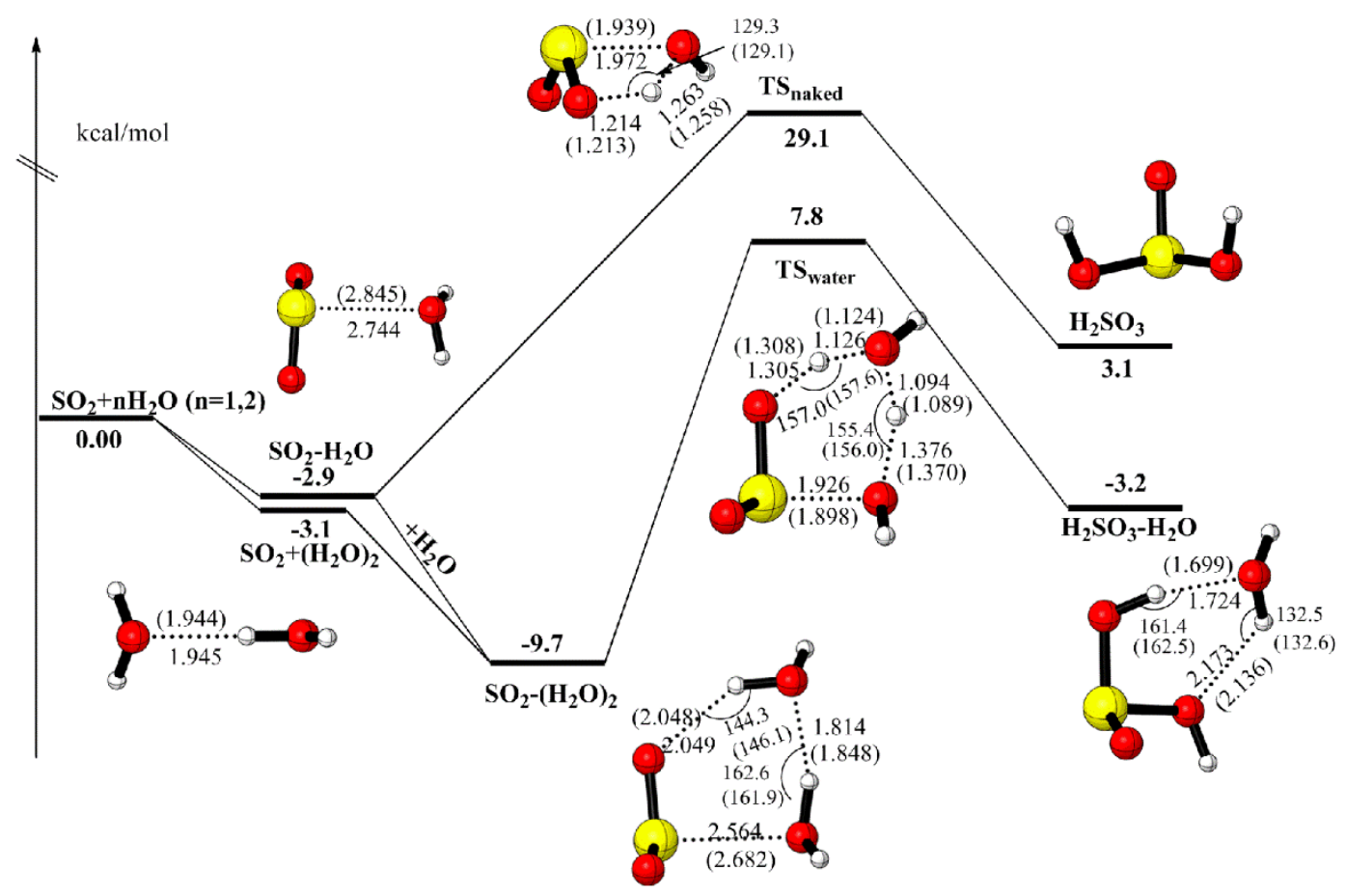

Figure 1.

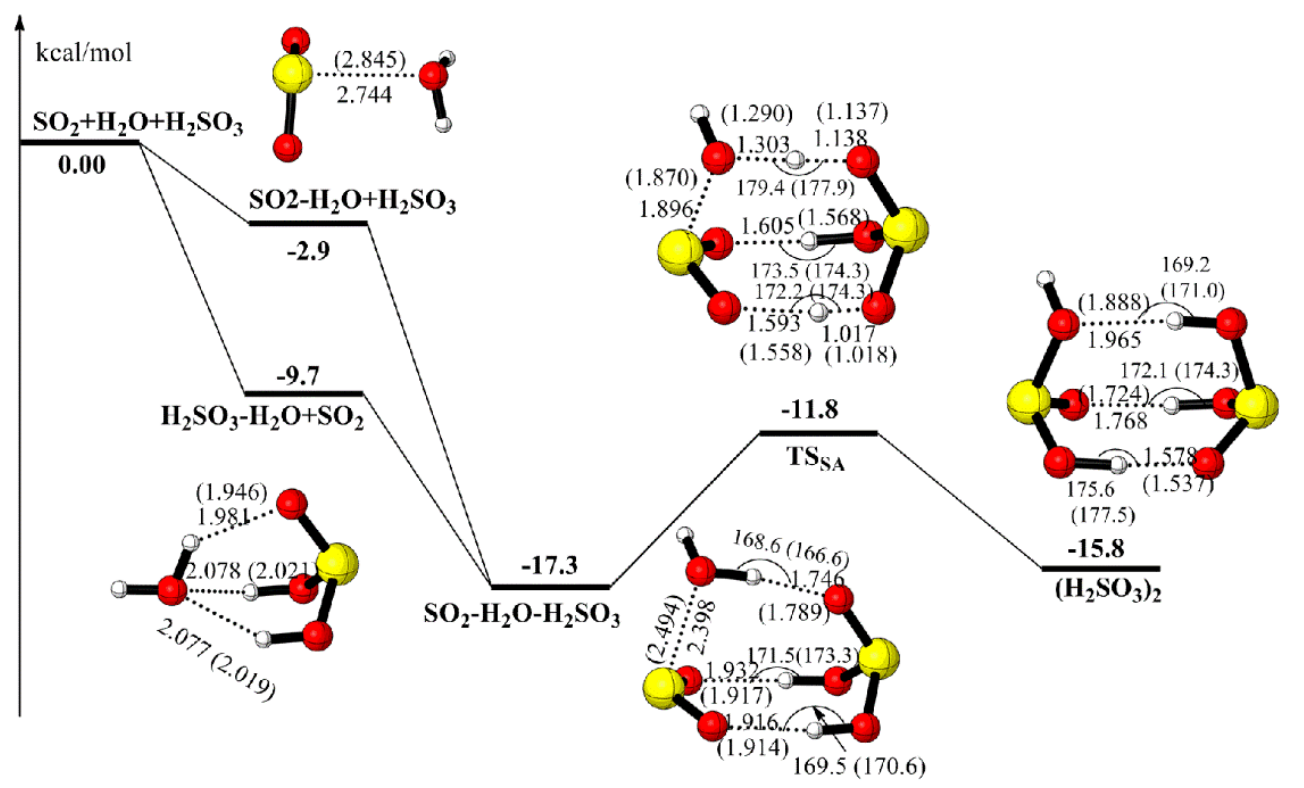

Figure 2. 
<smiles>O=S1O[C@H]2O[C@@H]1[C@H]2O</smiles>

$\mathrm{SO}_{2}-\mathrm{H}_{2} \mathrm{O}$

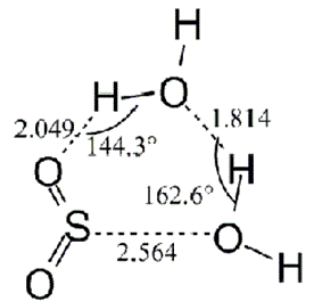

$\mathrm{SO}_{2}-\left(\mathrm{H}_{2} \mathrm{O}\right)_{2}$

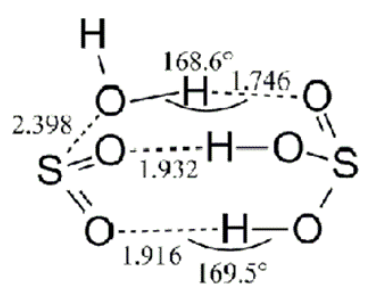

$\mathrm{SO}_{2}-\mathrm{H}_{2} \mathrm{O}-\mathrm{H}_{2} \mathrm{SO}_{3}$

Figure 3.

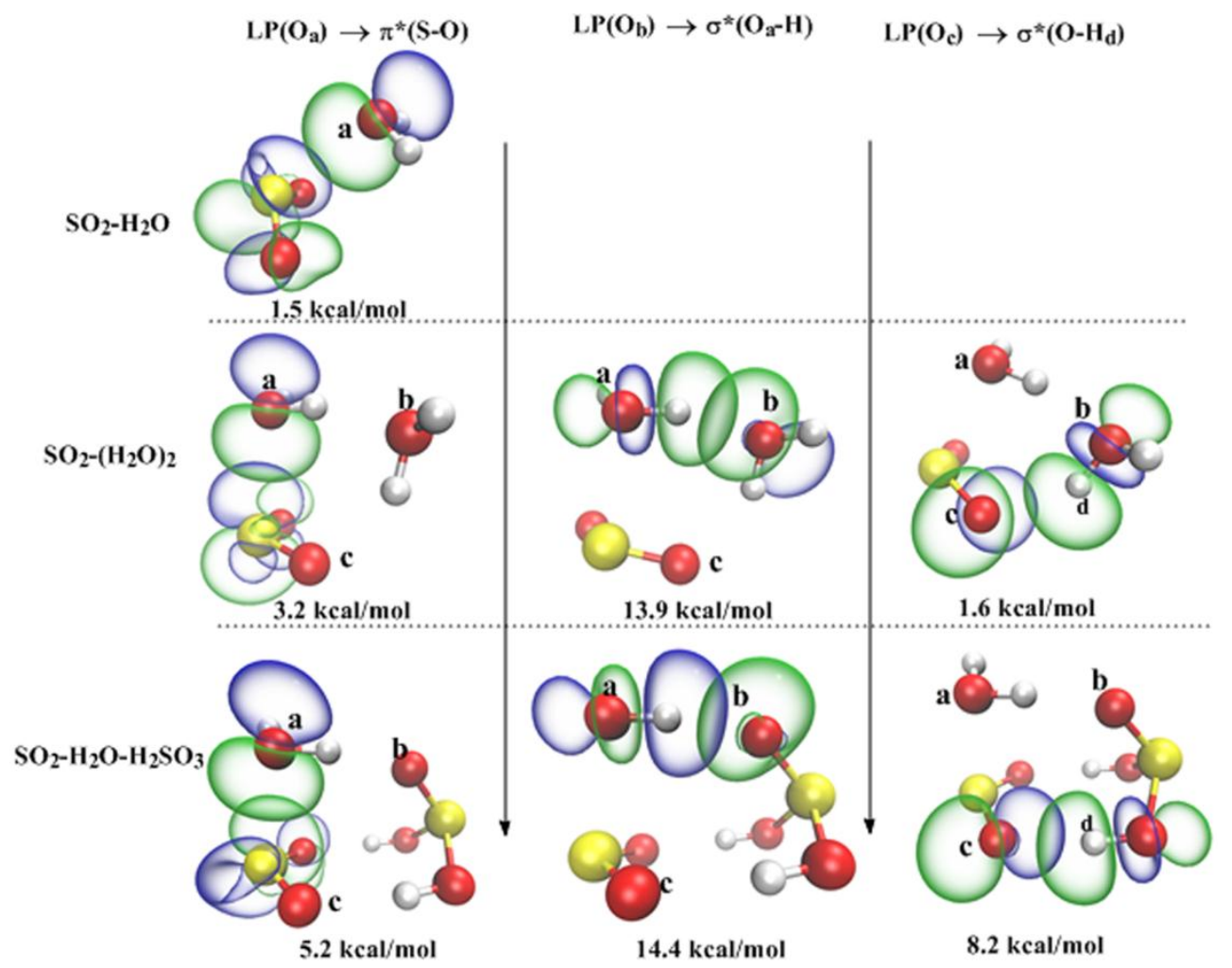

Figure 4. 
Table 1. Values of the equilibrium constant (Keq, in molecules $\left.\mathrm{cm}^{-3}\right)$, collision rate $\left(k_{1}\right.$, in $\mathrm{cm}^{3}$ molecule $\left.{ }^{-1} \mathrm{~s}^{-1}\right)$, unimolecular rate constant $\left(\right.$ kuni, $\left.\mathrm{s}^{-1}\right)$, and overall rate constant (ktot, in $\mathrm{cm}^{3}$ molecule $\left.\mathrm{s}^{-1}\right)$ for the reactions of $\mathrm{SO}_{2}-\mathrm{H}_{2} \mathrm{O}+\mathrm{H}_{2} \mathrm{O}, \mathrm{SO}_{2}+\left(\mathrm{H}_{2} \mathrm{O}\right)_{2}, \mathrm{SO}_{2}-\mathrm{H}_{2} \mathrm{O}+$ $\mathrm{H}_{2} \mathrm{SO}_{3}$ and $\mathrm{SO}_{2}+\mathrm{H}_{2} \mathrm{SO}_{3}-\mathrm{H}_{2} \mathrm{O}$ at the temperatures $\mathrm{T}=200-320 \mathrm{~K}$.

\begin{tabular}{|c|c|c|c|c|c|c|c|c|c|}
\hline \multirow{2}{*}{ Reaction } & & \multicolumn{8}{|c|}{$\mathrm{T}(\mathrm{K})$} \\
\hline & & 200 & 220 & 240 & 260 & 280 & 298 & 300 & 320 \\
\hline \multirow{3}{*}{$\mathrm{SO}_{2}-\mathrm{H}_{2} \mathrm{O}+\mathrm{H}_{2} \mathrm{O}$} & $\mathrm{K}_{\mathrm{eq}}$ & $2.16 \times 10^{-18}$ & $4.41 \times 10^{-19}$ & $1.18 \times 10^{-19}$ & $3.94 \times 10^{-20}$ & $1.55 \times 10^{-20}$ & $7.51 \times 10^{-21}$ & $6.79 \times 10^{-21}$ & $3.50 \times 10^{-21}$ \\
\hline & $k_{\text {uni }}$ & $4.66 \times 10^{-8}$ & $1.90 \times 10^{-6}$ & $4.06 \times 10^{-5}$ & $5.32 \times 10^{-4}$ & $4.75 \times 10^{-3}$ & $2.63 \times 10^{-2}$ & $3.14 \times 10^{-2}$ & $1.62 \times 10^{-1}$ \\
\hline & $k_{\mathrm{tot}}$ & $1.01 \times 10^{-25}$ & $8.35 \times 10^{-25}$ & $4.80 \times 10^{-24}$ & $2.09 \times 10^{-23}$ & $7.36 \times 10^{-23}$ & $1.97 \times 10^{-22}$ & $2.19 \times 10^{-22}$ & $5.67 \times 10^{-22}$ \\
\hline \multirow{3}{*}{$\mathrm{SO}_{2}+\left(\mathrm{H}_{2} \mathrm{O}\right)_{2}$} & $\mathrm{~K}_{\mathrm{eq}}$ & $1.75 \times 10^{-18}$ & $3.93 \times 10^{-19}$ & $1.15 \times 10^{-19}$ & $4.13 \times 10^{-20}$ & $1.74 \times 10^{-20}$ & $8.90 \times 10^{-21}$ & $8.31 \times 10^{-21}$ & $4.41 \times 10^{-21}$ \\
\hline & $k_{\text {uni }}$ & $4.66 \times 10^{-8}$ & $1.90 \times 10^{-6}$ & $4.06 \times 10^{-5}$ & $5.32 \times 10^{-4}$ & $4.75 \times 10^{-3}$ & $2.63 \times 10^{-2}$ & $3.14 \times 10^{-2}$ & $1.62 \times 10^{-1}$ \\
\hline & $\mathrm{k}_{\mathrm{tot}}$ & $8.17 \times 10^{-26}$ & $7.45 \times 10^{-25}$ & $4.66 \times 10^{-24}$ & $2.19 \times 10^{-23}$ & $8.26 \times 10^{-23}$ & $2.34 \times 10^{-22}$ & $2.61 \times 10^{-22}$ & $7.15 \times 10^{-22}$ \\
\hline \multirow{5}{*}{$\mathrm{SO}_{2}-\mathrm{H}_{2} \mathrm{O}+\mathrm{H}_{2} \mathrm{SO}_{3}$} & $\mathrm{~K}_{\mathrm{eq}}$ & $9.75 \times 10^{-12}$ & $3.56 \times 10^{-13}$ & $2.28 \times 10^{-14}$ & $2.25 \times 10^{-15}$ & $3.12 \times 10^{-16}$ & $6.66 \times 10^{-17}$ & $5.68 \times 10^{-17}$ & $1.29 \times 10^{-17}$ \\
\hline & $k_{1}$ & $3.41 \times 10^{-10}$ & $3.57 \times 10^{-10}$ & $3.73 \times 10^{-10}$ & $3.89 \times 10^{-10}$ & $4.03 \times 10^{-10}$ & $4.16 \times 10^{-10}$ & $4.17 \times 10^{-10}$ & $4.31 \times 10^{-10}$ \\
\hline & $k_{-1}$ & $3.50 \times 10^{1}$ & $1.00 \times 10^{3}$ & $1.64 \times 10^{4}$ & $1.72 \times 10^{5}$ & $1.29 \times 10^{6}$ & $6.24 \times 10^{6}$ & $7.35 \times 10^{6}$ & $3.34 \times 10^{7}$ \\
\hline & $k_{\text {uni }}$ & $5.33 \times 10^{5}$ & $1.56 \times 10^{6}$ & $3.75 \times 10^{6}$ & $7.79 \times 10^{6}$ & $1.44 \times 10^{7}$ & $2.32 \times 10^{7}$ & $2.44 \times 10^{7}$ & $3.84 \times 10^{7}$ \\
\hline & $k_{\mathrm{tot}}$ & $3.41 \times 10^{-10}$ & $3.57 \times 10^{-10}$ & $3.72 \times 10^{-10}$ & $3.8 \times 10^{-10}$ & $3.7 \times 10^{-10}$ & $3.28 \times 10^{-10}$ & $3.21 \times 10^{-10}$ & $2.3 \times 10^{-10}$ \\
\hline \multirow{5}{*}{$\mathrm{SO}_{2}+\mathrm{H}_{2} \mathrm{SO}_{3}-\mathrm{H}_{2} \mathrm{O}$} & $\mathrm{K}_{\mathrm{eq}}$ & $2.65 \times 10^{-21}$ & $4.64 \times 10^{-22}$ & $1.10 \times 10^{-22}$ & $3.30 \times 10^{-23}$ & $1.19 \times 10^{-23}$ & $5.36 \times 10^{-24}$ & $4.94 \times 10^{-24}$ & $2.32 \times 10^{-24}$ \\
\hline & $k_{1}$ & $4.10 \times 10^{-10}$ & $4.3 \times 10^{-10}$ & $4.49 \times 10^{-10}$ & $4.68 \times 10^{-10}$ & $4.85 \times 10^{-10}$ & $5.01 \times 10^{-10}$ & $5.02 \times 10^{-10}$ & $5.19 \times 10^{-10}$ \\
\hline & $k_{-1}$ & $1.55 \times 10^{11}$ & $9.27 \times 10^{11}$ & $4.08 \times 10^{12}$ & $1.42 \times 10^{13}$ & $4.09 \times 10^{13}$ & $9.33 \times 10^{13}$ & $1.02 \times 10^{14}$ & $2.24 \times 10^{14}$ \\
\hline & $k_{\text {uni }}$ & $5.33 \times 10^{5}$ & $1.56 \times 10^{6}$ & $3.75 \times 10^{6}$ & $7.79 \times 10^{6}$ & $1.44 \times 10^{7}$ & $2.32 \times 10^{7}$ & $2.44 \times 10^{7}$ & $3.84 \times 10^{7}$ \\
\hline & $k_{\mathrm{tot}}$ & $1.41 \times 10^{-15}$ & $7.22 \times 10^{-16}$ & $4.13 \times 10^{-16}$ & $2.57 \times 10^{-16}$ & $1.71 \times 10^{-16}$ & $1.25 \times 10^{-16}$ & $1.21 \times 10^{-16}$ & $8.89 \times 10^{-17}$ \\
\hline
\end{tabular}




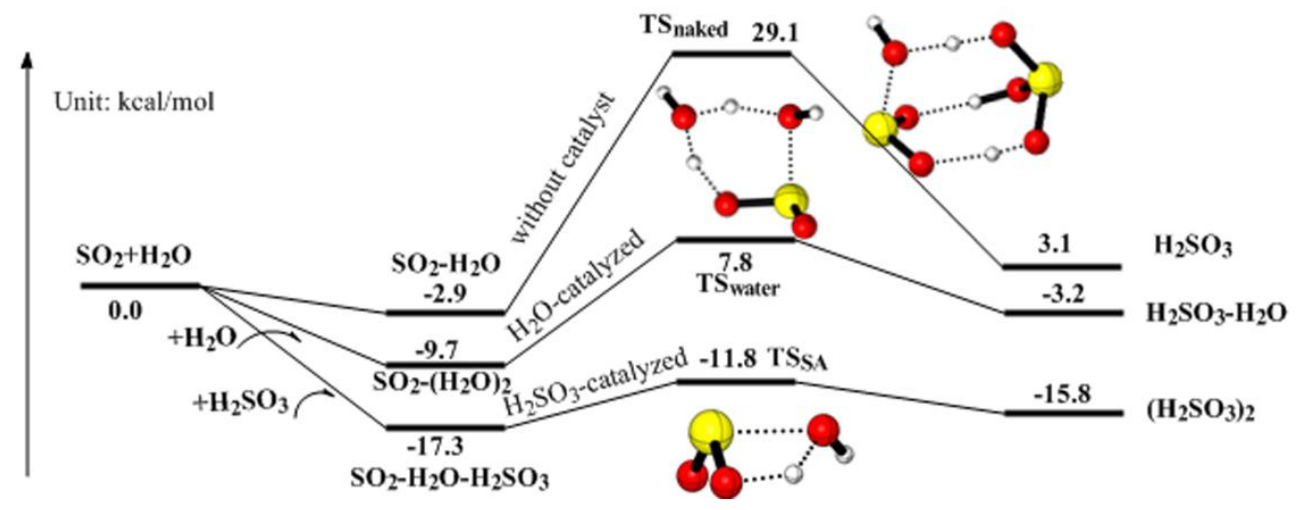

